\title{
PROSPECTIVE UPON MULTI-SOURCE URBAN SCALE DATA FOR 3D DOCUMENTATION AND MONITORING OF URBAN LEGACIES
}

\author{
E. Abbate ${ }^{12^{*}}$, G. Sammartano ${ }^{12}$, A. Spanò ${ }^{12}$ \\ ${ }^{1}$ Department of Architecture and Design (DAD) - Politecnico di Torino Viale Mattioli 39, 10125 Torino (Italy) \\ ${ }^{2}$ Polito FULL | the Future Urban Legacy Lab, Toolbox coworking. Via Agostino da Montefeltro 2, 10125 Torino (Italy) \\ emilio.abbate@polito.it; giulia.sammartano@polito.it; antonia.spanò@ polito.it
}

KEY WORDS: Data integration, multi-scale, multi-temporal, historical images data, geospatial archives, SDI, aerial photogrammetry, LiDAR data, urban morphology analysis, orthophoto, mobile-mapping, SLAM-based data, low-cost sensors

\begin{abstract}
:
The investigation on the built urban heritage and its current transformations can progressively benefit from the use of geospatial data related to urban environment. This is even more interesting when urban design studies of historical and stratified cities meet the contribution of 4D geospatial data within the urban morphology researches, aiming at quickly and accurately identifying and then measuring with a spatial relationship, both localized transformation (volumes demolitions, addition, etc...) and wide-scale substantial modification resulting from urban zones of diversification spaces that incorporates urban legacies. In this domain, the comparison and analysis of multi-source and multi-scale information belonging to Spatial Data Infrastructures (SDI) organized by Municipality and Region Administration (mainly, orthoimages and DSM and digital mapping) are a crucial support for multitemporal spatial analysis, especially if compared with new DSMs related to past urban situations. The latter can be generated by new solution of digital image-matching techniques applicable to the available historical aerial images. The goal is to investigate the amount of available data and their effectiveness, to later test different experimental tools and methods for quick detection, localization and quantification of morphological macro-transformation at urban scale. At the same time, it has been examined the opportunity to made available, with up-and-coming Mobile Mapping Systems (MMS) based on image- and range-based techniques, a rapid and effective approach of data gathering, updating and sharing at validated urban scales. The presented research, carried out in the framework of the FULL@ Polito research lab, applies to urban legacies and their regeneration, and is conducted on a key redevelopment area in northern Torino, the Parco Dora, that was occupied by steel industries actively working up to 1992 . The longstanding steel structures of the Ferriere FIAT lot have been refurbished and incorporated in the new urban park, generating a contemporary space with a new evolving urban fabric, and being integrated in the new updated geo-spatial databases as well.
\end{abstract}

\section{INTRODUCTION}

In last decades, the use of geospatial data related to urban areas has been not only the basis for analysis and updating of digital maps city databases, with the aim of create or update urban objects representation with increasingly accurate systems as well as fast and automated algorithms (Rottensteiner, 2014). Remote sensing sciences jointly with Geospatial Information Science (GIS) approach also support since many years the urban studies and urban planning research, to locate and relate, and mostly quantify complex phenomena, effectively supporting beyond their more traditional reading and representation. In particular, urban landscape is changing over years and architectural and urban design research recently foresee a recognized potential contribution to the urban morphology studies in the use of GIS approach and geospatial data pertaining urban areas, to spatialize transformation, to investigate urban phenomena behaviour related to the anthropized society and to monitor their transformations into a wider scale (Katsikis, 2014; Brenner, 2014). The new simulation approaches 3D oriented are the basis of the up-andcoming directions of urban policies for prediction and planning in smart cities, helping future decision-making processes. They found their effectiveness first of all in the provision of accurate and updated 3D models of the city in their geometry and semantics, i.e. 3DGIS. For this reason, the handling of 3D geospatial data as Digital Surface models (DSM) and building footprints from digital mapping is a crucial Geomatics purpose for the generation of accurate 3D city models (Macay Moreia et al., 2013). The main fields that frequently benefit from GISbased spatial data analysis, limited to the urban design and planning sciences are: accessibility, transport, urban greenery spaces, energy and resources, in particular for buildings, blocks and fabric morphology etc...(Torino Atlas, 2018).

The interdisciplinary research involving up-to-date geospatial data becomes even more complex when it comes to studying built heritage, in long time stratified urban and periurban landscapes in recent transformation, involving urban legacies. A typical phenomenon is the disposal of industrial areas and the problem of urban voids in the stratified urban continuum is a cutting-edge theme among urban morphology studies. A challenging purpose is to investigate both flexibility of existing traditional and digital maps products, as DSM and orthoimages, with mapping databases from private and public agencies, and integrated with to-be-implemented geospatial data by ad-hoc updating by sensing methods. In fact, the applied geomatics role, considering these urban legacies as cases of awareness in the built urban environment, should get up from the building's scale and propose some reasoning and effective methods about a new fitting approaches for urban monitoring, thus what could be essentially available in a geospatial city database to map at different scales morphological changes over recent times.

In this framework, the research is carried out in the northern area of Turin, the so-called Parco Dora, as a representative location that has been involved in the huge transformation of Spina3. This area of around $360.000 \mathrm{~m}^{2}$, evolved in last tens of years, from Nineties up today, in a new arrangement of residential/services zone. The attempt is to propose and evaluate the role of multi-scale urban data analysis and gathering for map updating by means of documentation and large-scale data collection. This will be divided in two main steps: the analysis 
of multi-temporal DSM for Change Detection (termed hereafter CD) for the location of micro- and macro-urban morphology transformation (Par. 3), and then, the possibility to operate in these noteworthy areas not easily accessible by means of car vehicles, with cutting edge solution of Mobile Mapping Systems (MMS) for image- and range-based urban 3D modelling (Par. 4).

\section{GEO-SPATIAL DATA SUPPORTING URBAN MORPHOLOGY MONITORING STUDIES}

The problems of performing multi-scale and multi-temporal analysis of the present-day city is firstly related to spatial and temporal resolution and coverage of data, namely, which resolution is suitable for which phenomena, also in case of multitemporal frames for detecting urban changes. Conventionally, the remote sensing approach in last tens of years is working with image- and range-based data. The data processing is conducted in order to analyse, to segment and to classify 2D data derived from spaceborne and airborne images (orthoimages classification, segmentation) and 3D surfaces (DSM/DEM filtering, classification, segmentation) and to relate attributes to them addressed to automatically derives urban objects: i.e. mainly building, vegetation, terrain etc. It takes place mainly working, respectively or jointly, on radiometric and morphological surface features analysis and detection. The use of initial data is mostly attributable to the required scale, to the spatial/temporal dimensions and actually to the data availability. It is wellrecognized that the use of airborne LiDAR data is always in the last tens of years the most diffuse sensing technique for 3D modelling at urban scale (Vosselman\&Maas, 2010). In literature, countless cases presented experimental approaches for integrated data processing that normally requires DSM filtering and optimization, point cloud classification and object-based derivation of building objects (Xu et al., 2013; Pu\&Vosselman, 2008). Recently, the contribution of Mobile Mapping Systems (MMS) equipping mainly vehicles or portable devices in urban scenes has foreseen the integration of more quick approaches and more close-range information to update numerical data and urban 3D reconstruction: the use of fusion-based data by imaging and LiDAR sensors and 3D mapping unit mounted on vehicles systems and, furthermore, the integration of closeheight aerial images by UAV photogrammetry. Many studies, in fact, tackle the possibility to integrate the different data deriving from aerial and UAV photogrammetry with MMS technique, aiming to build a 2.5D DSM surface model and 3D city models, especially in built heritage (Toschi et al., 2017, Gruen et al., 2013, Puente, 2013, Haala et al., 2008). More recent fusionbased approaches that make use of low-cost and portable mapping system solutions have appeared and overlook the survey the urban heritage environment at the building scale; they provide appreciable 3D data spatially focused on building and aggregates (Next par.4).

\subsection{Torino: industrial legacy and urban transformation}

In these directions, the purposes and needs for urban data gathering, updating and monitoring are investigated in Torino as archetypal industrial city of last century, which has been involved in the last decades until today in many crucial transformations of its industrial memory, impacting in its future appearance of technological city attentive to its cultural legacies.

The research focused on the northern area of Turin along the Dora river course, and wonders about the actual role of largescale data collection and documentation, analysis and data updating task, divided in two main steps (faced in next Par. 3-
4). Due to its recent urban transformation, this peripheral area called Spina 3 according to 1993 P.R.G - represents a suitable case study for the present research (Vera Nocentini, 2010).

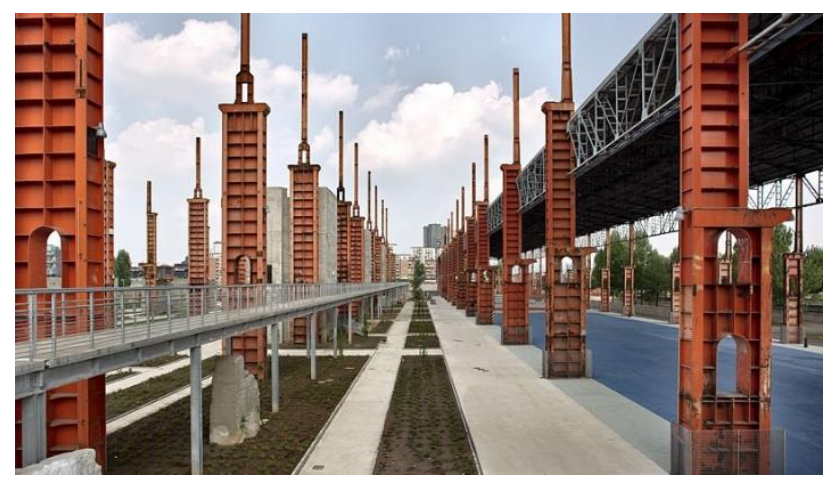

Figure 1. Ex- strippaggio factory, Teksid area

The Dora Park area is characterized by the presence of few legacies of the industrial past of the area: the ex-factory of the strippaggio, the cooling tower of the French company Michelin and the plant of Officine Savigliano, recently refurbished. Moreover, a large garden supporting a steel walkway that allows the connection between the terrace of the Mortara lot and the Ingest area, is located around to the ex-factory of Strippaggio (Ferriere FIAT area, Vitali lot, $89000 \mathrm{mq}$ ). This area contains a multifunctional space suitable for hosting events and sport activities (Figure 1). In fact, this area, revitalized by young skaters and families who enjoy the park, represents today the legacy of the recent past: the remains of the endless huge metal structures and unreachable roofs, as well as being a fascinating and instructive scenario, have a formative value for the community by recalling the places of abandoned work, together with the earlier social and economic development. In this area in fact are placed few industrial pre-existing structures belonging to the ex-factory of the Strippaggio of the Teksid steelworks complex, such as the steel pillars useful to sustain a massive steel roof. This area is the result of the transformation process of the city, started in the first mid-nineteenth century and still in effect today. At the time, the Italian company FIAT acquired the Vitali lots calling them Teksid area. Later, despite the bombardments of the World War I on the city, the activities of the factories of the Ferriere FIAT didn't cease, continuing the production until 1989 (FIAT, 1937). In the 1992 the company definitively stopped the production activity and the plants were partially demolished in 2005 .

\subsection{Gathering available large scale data in Torino SDI}

In the 2000s, when the adoption of geographic data infrastructures (Groot \& McLaughlin, 2000) was affirmed at an international level, the Piedmont region and the municipality of Turin, which could then make use of an intermediate cartographic service consisting of the province, could count on an allocation of data and services rather rich and endowed with a certain maturity in the field of harmonization of the reference systems and restructuring of the data models according to standards. Schematically citing the main developments that have occurred:

- adoption of the data model consistent with the Intesa GIS model complying with the ISO-TC 211 standard and later partial restructuring according to the INSPIRE standard for regional numerical mapping.

- extensive project started in the 2000s of geometric harmonization and reference systems of cadastral mapping with municipality technical digital map.

- aerial photogrammetric flight (2009-2011 with Leica ASL camera) and production of a regional orthophoto and DTM which later allowed the development of projects for controlling 
related issues such as land consumption and environmental risks.

- release of geoservices from the OGC: Web Map Service (WMS), which enables simultaneous display and overlap through geodata http protocol or represented physical fields from raster maps from multiple different and distributed servers. http://www.geoportale.piemonte.it/cms/servizi/servizi-di-consultazione. The study concerning the area of the refurbished ex-Teksid manufacturing lot, started with a wide investigation to clarify the potential 2D and $2.5 \mathrm{D}$ data useful for carrying out an application that allows to monitor over time the physical changes of places starting from orthophotos, DTMs, historical frames and numerical maps based on geo-spatial DB of different updates.

Scales, resolutions, coverages, dating, reference systems, and availability featuring data, have been taken into attentive account. In figure 2 some example of different time data: the historical national maps (1880-1882 the former in Italy) with the buildings geo-spatial dataset superimposed. The next pictures represent three different epoch orthophotos (1979, $1990,2018)$ providing the ability of visual comparison in distinct temporal frames
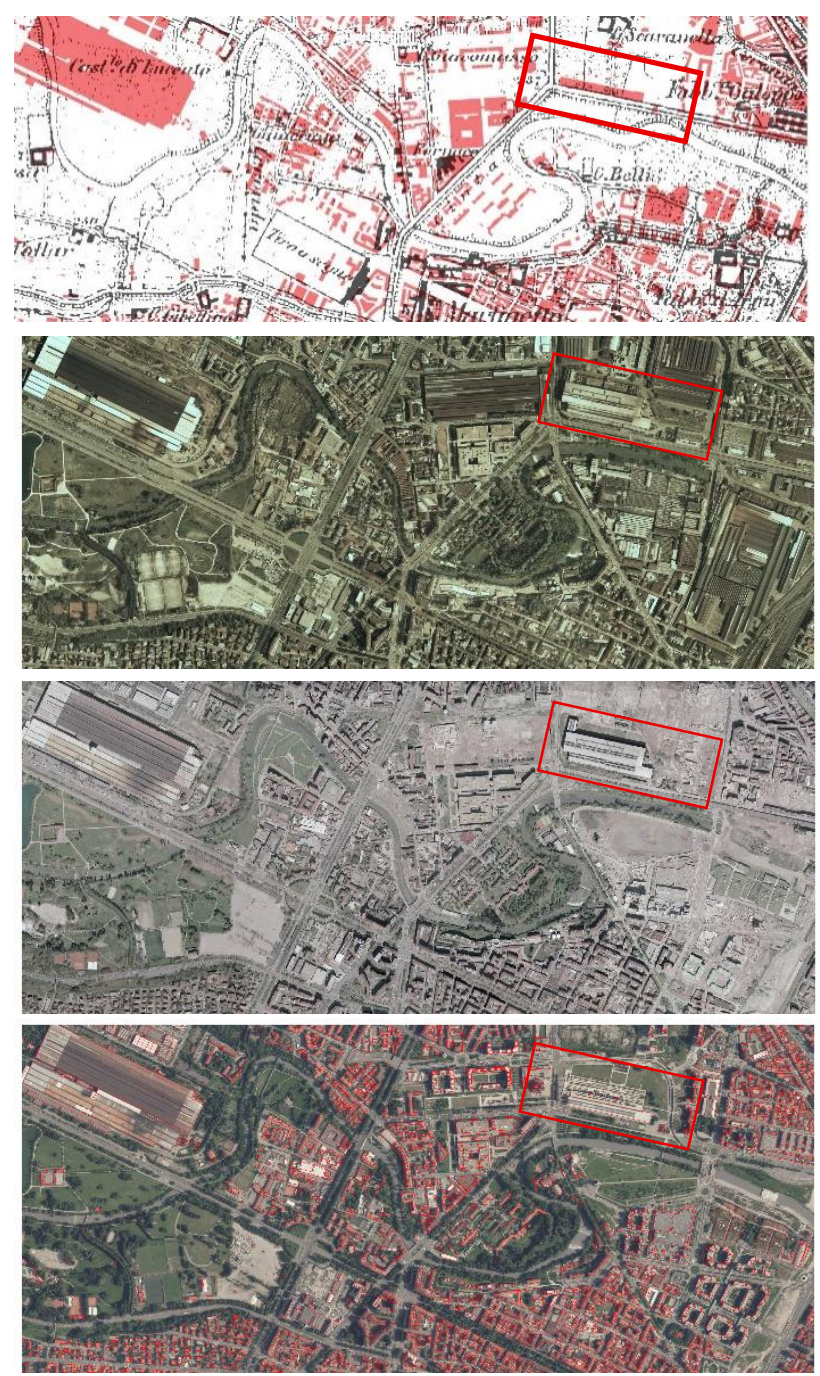

Figure 2. Multi-temporal geospatial data from Torino SDI Geoportal: 1880-1882 IGM, 1979, 2004, 2018.

\section{MULTI-TEMPORAL DATA ANALYSIS AND URBAN TRANSFORMATION}

The challenging aim of this data handling is the performing of a multitemporal analysis of change detection (CD) looking at Torino test area through the use of multi-temporal dataset. The preliminary detection, localization and quantification with a fast experimental method, detect morphological macrotransformation at urban scale proving urban analysis and urban design studies. The approach considers however problems derived from the dissimilar initial data in terms of accuracy and resolution and some uncertainties on results. These are taken into consideration for further improvements specification from a methodological point of view.

\subsection{Change detection (CD) approaches and guidelines}

In literature, traditional 2D CD in urban areas is normally imagebased using spectrum analysis of medium-to-low up to high resolution satellite images in order to undertake large-scale phenomena. They are basically developed in numerous integrated approaches with the purpose of extracting features between two temporal states and thus measure changes over years i.e. for mapping production and Geo-databases (GDB) updating, as in (Bouziani et al., 2009). Limits that typically affect image-based analysis for $2 \mathrm{D} \mathrm{CD}$ are the variance of radiometric values (better to use the same seasonal time-window), the influence of images distortion (better to use top view data) and the effective loss of the 3D dimension (only planimetric changes can be considered as reliable for large-scale phenomena).

Thus, in the test case here presented DSM data are preferred as initial 3D data for CD application. In fact, a 3D multi-temporal assessment extract and quantify difference in the $2.5 \mathrm{D}$ or fully $3 \mathrm{D}$ from image-derived or LiDAR-based point clouds DSM. A comprehensive review of 3D CD methods and state of the art can be found in (Qin et al., 2016). Usually, DSM data acquired from airborne LiDAR was often use to detect the urban morphology modifications in time-windows dataset (Matikainen et al., 2010). Since (Murakami et al., 1999) it can be retrieved an effective CD of urban building using aerial DSM LiDAR based on pixel-based difference and the research literature is very rich in this regard. However, a comparison between image- and range-based 3D data is also possible, as in (Stal et al., 2011), where a DSM extracted from stereoscopic aerial images and a DSM derived from airborne LIDAR data by pixel-wise subtraction is presented to quantitatively compare surface 3D models in order to verify urban environment transformations and to indicate changes in elevation, quantifying volume changes.

It can be summarized that the correct procedural approach to perform 3D CD should take into condensation many factors, depending on the purpose as well, such as:

1) Different type of initial data, carrying on different intrinsic features, e.g. heterogeneousness of reliability and resolution, lead to attentive approaches. They influence the accuracy of derived information (Stal et al., 2011). Here different sensorbased DSM will be analysed and compared.

2) 3D data derived from image-matching approaches (MSM or MVS) (Remondino et al., 2014) can suffers from noise errors and filtering approaches can be implemented for data correction. Here a DSM derived by image-matching approach performed on historical images will be presented.

3) $\mathrm{CD}$ results can be biased by the crucial problem of data coregistration, i.e. the correct alignment of the DSM (Akca, 2007). Here, the georeferencing issues have been considered due to the high-scale of this urban data and the modification of reference system, non-uniform along the considered timewindows. 
4) The morphology of the investigated area influences the final difference accuracy of extracted pixel objects. It depends also from type of urban areas (as historical urban blocks, as in the test case), were occlusion and vegetation can cause occurrence of noise and artefacts outliers.

5) The selection of the difference method is crucial and depends on the initial data. Despite geometric comparison of pixel groups can been supported by a geometry-spectrum analysis (Qin et al., 2016), here the only geometric comparison is performed according to values differences. Euclidean difference involves fully 3D data according to the surfaces normal but are strictly influenced by outliers caused by data poor co-registration. Instead of it, the height difference, here employed, considers the vertical comparison between height values of DSM. This last approach considerable suffers from noise errors at the objects borders.

6) The approach to the detection could be pixel-based or object based according to the application and the data resolution. Many approach consider the post segmentation and classification procedure to detect the types of changed pixel regions between the time-periods (Teo\&Shih, 2013).

Recently the MSM or MVS image-matching methods provide a potential exploitation of historical archives images and available SW packages, helped by advanced dense matching algorithms for point clouds DSM extraction (Feurer\&Vinatier, 2018). The crucial tasks for using digitized historical images are essentially the variables concerning: the film digitization by photogrammetric scanner, the original estimation of internal and external orientation parameters and mostly the absolute positioning in order to compare it with more recent data, and to made coherent the DSMs belonging to different epochs according to the co-registration principle. The possibility to extract metric values from multi-epoch aerial images with image-matching principles is faced by means of different approaches in quite recent literature researches. Once digitized, they can be useful for calculation of new DSMs related to past urban settings, to be compared with the actual state too (Nebiker et al., 2014; Adami, 2015; Nocerino et al., 2012). Particularly, the use of multitemporal archival data is faced in (Patias et al. 2011), performing a $C D$ in historical city centres for land use comparison and classification. Multi-temporal photogrammetry lead to a GISdriven spatial analysis applied to historical datasets for urban development strategies and planning too (Turek et al., 2018).

\subsection{Initial data selection and $\mathrm{CD}$ pre-processing}

Here, the three types of DSM data (Figure 3) related to different times have been selected for the multi-temporal analysis, among the available and accessible data, and termed as following:

- T1: 1990, DSM $_{\mathrm{SfM}}$

T2: 2004, DDEM (Dense Digital Elevation Model)

T3: 2009, DSM $_{\text {LiDAR }}$

T1) The $\mathrm{DSM}_{\mathrm{SfM}}$ originates from historical photogrammetric flight images completed in 1990 and with a corresponding $\mathrm{GSD}=0.5 \mathrm{~m} / \mathrm{px}$ but with an overall accuracy of $1 \mathrm{~m}$. It refers to the photogrammetric process in following Par. 3.2.1.

T2) The DDEM derived from an automated procedure presented in (Biason et at, 2004) to extract the accurate orthophoto of Torino city, and was calculated on the basis of the 3D digital base map at 1:1000 scale of the city of Torino at that time, (polygons with elevation point at ground level and height). The DDTM had a pixel size of $20 \times 20 \mathrm{~cm}^{2}$, (suitable for 1:2000 scale orthophoto).

T3) The DSM $\mathrm{LiDAR}_{\text {was }}$ acquired and elaborated between 20082009 and then distributed by Italian Ministry MATTM (www. minambiente.it) according to INSPIRE dir. The airborne LiDAR acquisitions were performed with national coverage and with the purposes of surveying and monitoring the river courses as areas with high hydrogeological risk, under the "Extraordinary plan of environmental remote sensing" (Dc. law n. 179/2002, art. 27)

The used $\mathrm{DSM}_{\mathrm{LiDAR}}$ is the $\mathrm{DSM}_{\text {last }}$ impulse, with ground resolution equal to $1 \times 1 \mathrm{~m}$ and was included in the test the overflown area related to the Dora river dated back to 06/2009

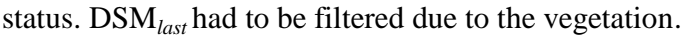

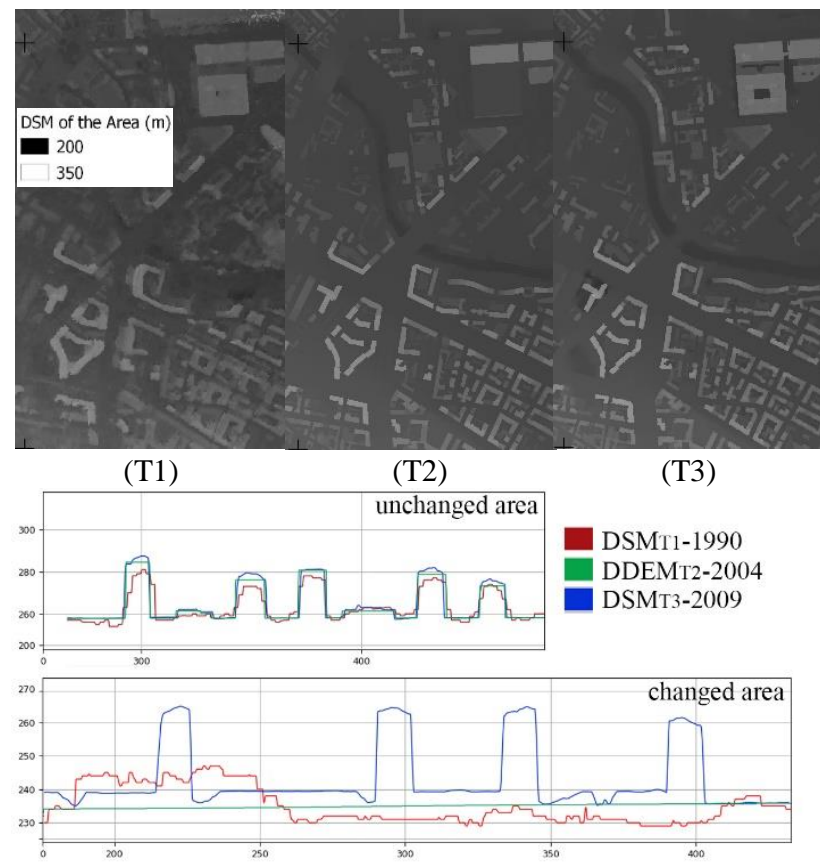

Figure 3. The three DSM data considered at the T1, T2 and T3

3.2.1 DSM for past urban landscape: boosting/enhancing historical images with 3D dense matching

A rich database of historical airborne images is archived by the Piemonte Region administration, partially investigated yet by (Cassatella et al., 2015), and a dense package pertain the urban area of the Torino, the hill and the metropolitan area. Among the available photogrammetric flights 1936, 1957, 1968, 1979, 1990 , etc....and more frequent ones, one per year, in recent times, a selection of strips at a feasible dating for useful CD have been chosen, i.e 1990 set of images. These images have been processed to obtain a new DSM concerning the past physical situation exploiting recent tools of digital photogrammetry and image-matching algorithms, by means of digitalized aerial photograms.

The photogrammetric flight was performed in 1990 by Città di Torino for mapping updating and orthoimage documentation purposes. Ali Toscane company was equipped with a ZEISS RMK-A 15/23, a calibrated standard wide angle aerial camera, with focal length $153 \mathrm{~mm}$ and $23 \times 23 \mathrm{~cm}$ film. The flight plan was performed with a fight height of around $1800 \mathrm{~m}$ for a map scale 1:10000, organized in total of 16 photogrammetric strips (20\% sidelap, $60 \%$ endlap). The negative films were digitized at 800dpi with non-photogrammetric scanner, and distributed by the Turin municipality in $7244 \times 7244 p x$ images (Figure 4).

A block of images has been selected on the focus area and 40 images have been employed in order to recreate internal and external orientation and to compute a numerical DSM dated back at 1990 , called $\mathrm{DSM}_{\mathrm{SfM}}$. The bundle block adjustment, was performed using a set of $n^{\circ} 20$ plano-altimetric points selected from the fix topographic reference points and recognisable on the aerial images as Ground Control Points (GCP) and Control 
Points CP (Agisoft Photoscan ${ }^{\circledR} \quad 1.4$ GUI was used https://www.agisoft.com/).

The restrained radiometric quality of images, in addition to the low overlapping of adjacent images in use years ago, provided good RMSE on GCP and CP (Table 1) but a rather unprecise DSM $_{\mathrm{SfM}}$, affected by noise errors and big outliers, especially near vegetation areas and narrow blocks and tall buildings, that requested a filter for optimization downsampling (Convolutional filter, median; kernel size $6 \times 6 \mathrm{px}$ ).
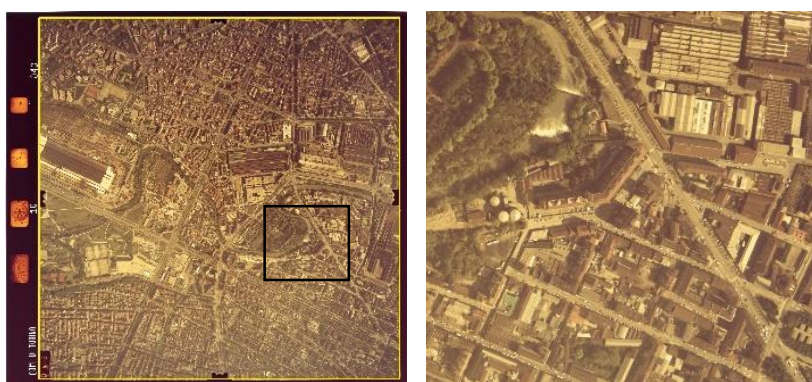

Figure 4. (left) An example of the aerial images from 1990 photogrammetric block and the cropped area in yellow,

23x23cm; (right) A zoomed excerpt of the southern Dora area

\begin{tabular}{|l|c|c|c|}
\hline & \multicolumn{3}{|c|}{ Bundle block adjustment RMSE } \\
\hline \multicolumn{1}{|c|}{$(\mathrm{m})$} & $\mathrm{X}$ & $\mathrm{Y}$ & $\mathrm{Z}$ \\
\hline $\mathrm{N}^{\circ} 15 \mathrm{GCP}$ & 0.324 & 0.402 & 0.373 \\
$\mathrm{~N}^{\circ} 5 \mathrm{CP}$ & 0.327 & 0.278 & 0.617 \\
\hline
\end{tabular}

Table 1. RMSE on measured GCP and CP

\subsubsection{DSM difference and preliminary CD control}

The CD process, alongside the optimization and resampling procedures, were performed by pixel-wise subtraction with algorithms of raster difference implemented in SAGA GIS software interface (QGIS 3.2). The derived products are named below Digital Surface Model Difference (DSMD).

$\mathrm{DSMD}_{\mathrm{T} 2 \mathrm{~T} 1}$ was fulfilled to detect and locate volumetric differences between 1990 up to 2004. Parallely, DSMD ${ }_{\text {T3-T2 }}$ returns differences occurred between 2004 and 2009. A sample area of DSMD along the Dora river bend concerning the industrial complexes, relatively to Figure 3, is showed in Figure5.

The resulting DSMDs have been optimized with morphological filter, Square kernel mode, 2 cells radius, erosion method.

Thresholding values in changes classification and representation are carefully pondered because of the original problem of quality of the $\mathrm{DSMD}_{\mathrm{SfM}}$ initial data. Consequently, 5 classes have been selected to represent the post detection and classification. Values $<5 \mathrm{~m}$ are considered under reliability threshold and thereby not visualized (negative values too, associated to volume subtraction, demolishment, are not currently considered here in the representation). In this way, however, all the information relating the medium-little modifications as superelevations are lost.

A preliminary proposal for the check of the uncertainty relative to the $2.5 \mathrm{D}$ component in DSM difference and derived values useful to quantify the changes is reported below.

The use of the volumetric entities (020101_Unità Volumetrica) from digital mapping of Torino is employed for values for rough control. After the automatic computation of values from the zonal raster statistics from the difference e.g. DSMD $_{\mathrm{T} 3-\mathrm{T} 1}$ with the topological properties of vector footprint, each polygon assumes the mean, median, and standard deviation of each contained pixel of $\mathrm{DSMD}_{\mathrm{T} 3-\mathrm{T} 1}$. Then, the attribute from $\mathrm{CD}$ values is associated with the attribute "Volume height" related to the vector polygons (Figure 6). They are assumed as positives the polygons with median $>7 \mathrm{~m}$, namely those polygons that between 1990 and 2009 undergone a positive modification of volume height more than $7 \mathrm{~m}$.

The guidelines in force in Italy (Brovelli et at., 2009) for the accuracy evaluation of orthophotos and DTMs production foresee the strategy of determining a network of CP using measurement techniques featured by precision equal to an order of magnitude higher than the product to be assessed. Since our test was not intended to produce a new DTM for mapping purposes but rather a thematic dataset locating urban changes was detected, some abovementioned sample checks were carried out, and figure 6 shows very good correspondences between the medians of pixel height values and the heights of the buildings polygons.

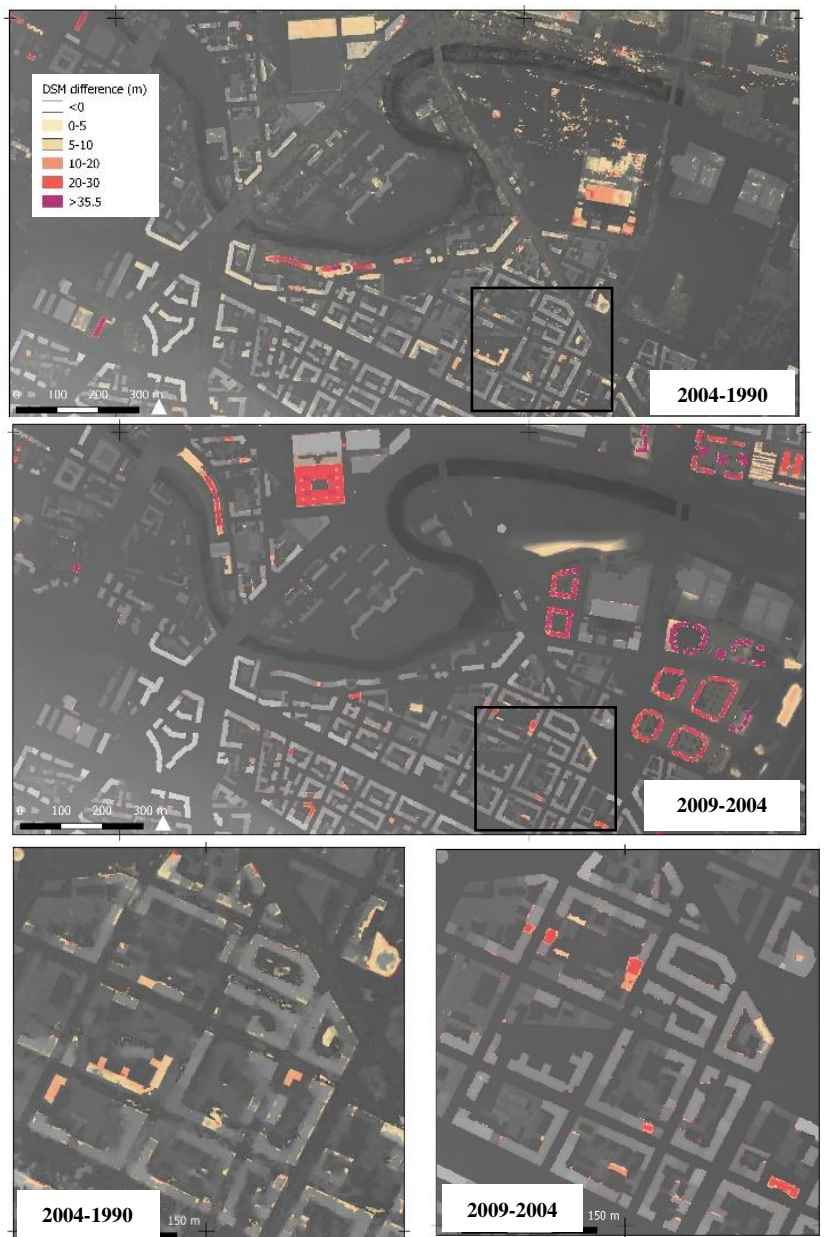

Figure 5. (top) The DSMD ${ }_{\mathrm{T} 2-\mathrm{T} 1}$ superimposed to $1990 \mathrm{DSM}$ and (centre) DSMD $\mathrm{T}_{\mathrm{T} 3-\mathrm{T} 2}$ superimposed to 2004 DSM. (bottom) Zoomed excerpts of the $\mathrm{DSMD}_{\mathrm{T} 2-\mathrm{T} 1}$ and $\mathrm{DSMD}_{\mathrm{T} 3-\mathrm{T} 2}$

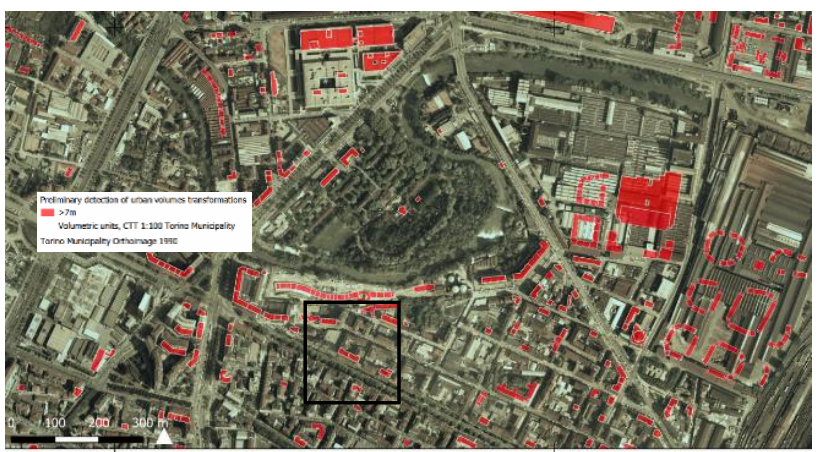




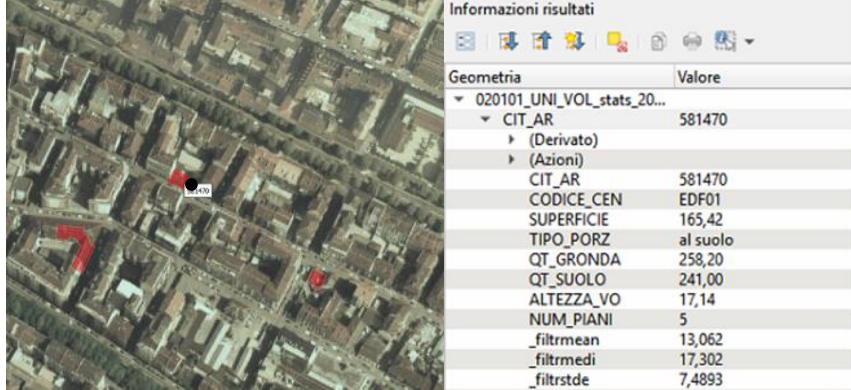

Figure 6. Correspondence check between DSMD statistical values and digital mapping of Torino, red. Volume data analysis on a sample with attribute about "Volume height"

\section{BUILDING SCALE DATA INTEGRATION}

The new configuration of the urban landscape can be effectively documented integrating high-scale updated data acquired by rapid terrestrial approaches. In addition to the urban scale products and the chances to manipulate them with the purpose to deepening large-scale phenomena, from a close-range perspective new methods for active and passive sensors data collection are available. Terrestrial LiDAR, UAV photogrammetry or vehicles-based and portable MMS (Calantropio et al., 2018; Nocerino et al., 2017; RodríguezGonzálvez et al., 2017; Micusik\&Kosecka, 2009; Tucci et al., 2018) are perhaps the most used in case such the present, namely when urban equipment, park-equipped public spaces or the remains of these cathedrals of past labour need to be surveyed. These use-oriented models capabilities would be highlighted: primarily the possible updates applicable to the urban technical map and the integration of navigable models in web-based crowdsourcing systems such as Streetview or Mapillary where these and similar circumscribed city scenarios are often not documented.

\subsection{MMSs for urban digital map updating}

The potential metric role of some portable and low cost-based solutions, faced in many occasions in which metric and radiometric parameters of the derived products from these systems have been evaluated as proficient for an urban scale mapping, have been highlighted in this paper, with their descriptive and communicative abilities of the derived models.

The use of a portable SLAM-based mapping system, ZebREVO RT with embedded ZebCam (Par.4.1.1);

V10 Trimble (https://www.trimble.com/), GNSS imaging rover mapping system for metric purposes (Cera et al., 2017)

a spherical camera, Fusion $360^{\circ}$ Gopro (https://it.gopro.com/) (Kossieris et al., 2017) generating SfM-based acquisition

Particularly, Trimble V10 Imaging Rover represents a closerange and rapid-mapping instrument able to generate $360^{\circ}$ digital panoramas, trough twelve calibrated cameras. The resulting $60 \mathrm{MP}$ panorama images can be used for photogrammetric measurements. The Fusion $360^{\circ}$ camera is used in order to extract a set of spherical panoramas (two fisheye hemispheres from each acquisition) from a non-stop acquisition (one panorama/2seconds walking) (Figure 7).

To survey entire ex-factory of strippaggio were needed: 84 spherical images and 67 image station points.

Concerning the V10 acquisition, for each position, the $\mathrm{X}, \mathrm{Y}, \mathrm{Z}$ coordinates are captured by topographic measurements and with GNSS data (stations outside the shed) according to reference system adopted. Instead, the bundle adjustment of spherical images is performed with 6GPC using the 3D dense image matching of Agisoft Photoscan GUI. On the other hand, into Trimble Business Center software, the photo-stations were adjusted in order to guarantee highest level of accuracy among photo station vertices thanks to manual and automatic tie points detection. Then, after defining possible depth planes, it is possible to detect and create the vector polygons directly on panoramic images to retrieve the steel pillars 3D shape (Figure 7), that can be export aiming at urban digital maps updating. Moreover, it is possible to perform the images adjustment for the generation of a dense cloud.

Both from oriented spherical images block and from imaging station adjustment, the preliminary evaluation on geometry accuracy demonstrates possible use of this $3 \mathrm{D}$ reconstruction for urban scale purposes (V10: mean errors on vertices adjustment are $\mathrm{X}=0.2 / \mathrm{Y}=0.1 / \mathrm{Z}=0.05$. Fusion $360^{\circ}$ : mean errors on $\mathrm{GCP}$ are $\mathrm{X}=0.02 ; \mathrm{Y}=0.03 ; \mathrm{Z}=0.02$ )

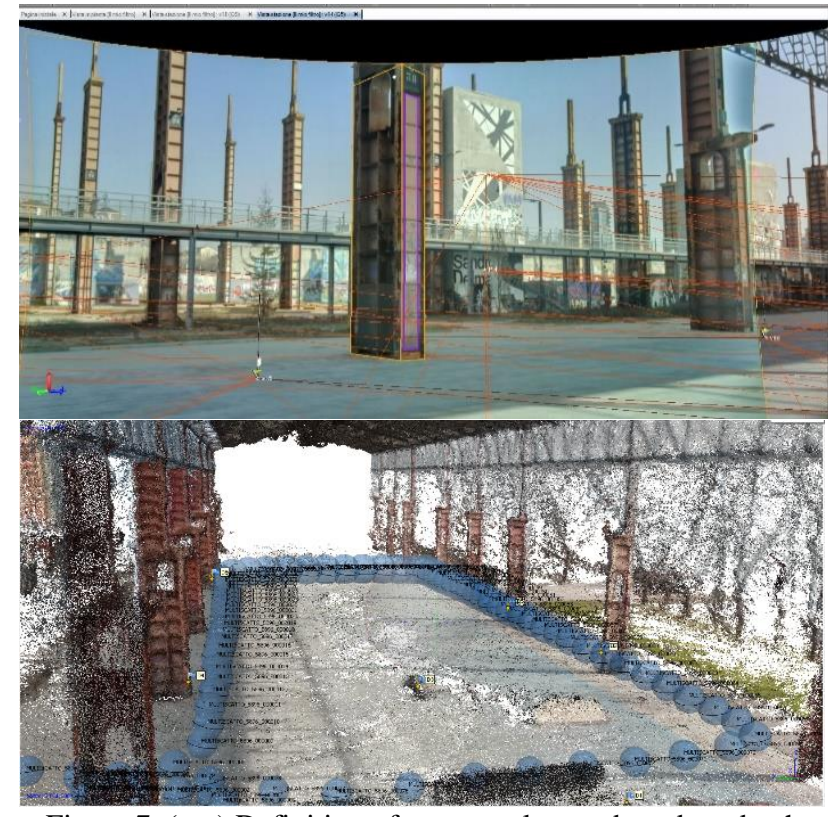

Figure 7. (top) Definition of vector polygons based on depth planes from V10 panoramas; (bottom) GoPro spherical cameras alignment, GCPs and derived dense cloud

\subsubsection{SLAM-based mapping acquisition}

The simultaneous Localisation and Mapping (SLAM) -based mobile mapping system called ZEB Revo by GeoSLAM ${ }^{\mathrm{TM}}$ is a handheld 3D scanner (Zlot et al., 2014). It belongs to some portable solutions that have been developed in the last years mainly for close-range mapping of indoor building spaces and of enclosed or underground environments. The pulsed light beams travelling from the sensor to the object and back, are simultaneously aligned during the trip by the registration algorithm implemented in the system and based on 3D SLAM robotics technology. The algorithm works for both the trajectory incremental motion estimation and global points cloud registration along the trajectory. In general terms, good performances in outdoor environments are reachable (Sammartano\&Spanò, 2018), but the huge spaces of the exstrippaggio factory, the high distances between pillars and the height of the roof put extra strain on this system, which guarantees good results when the objects to be detected are positioned at a distance compatible with its capacity which is $\mathbf{1 5}$ $\mathrm{m}$ approx. Nevertheless, the images of figure 8 show the points cloud with the closed trajectory highlighted in red, and the corresponding possible horizontal and vertical sections extracted from the cloud. The test comparison with technical 
digital map 1:1000 in figure 9, demonstrates capabilities for mapping updating 1:500-1:200 scale up to an increased building scale 1:100-:1:200. The scans lasting 15-20 minutes and they can constitute an important and rapid basis for deriving position and shape of aerial paths entering inside the structure.

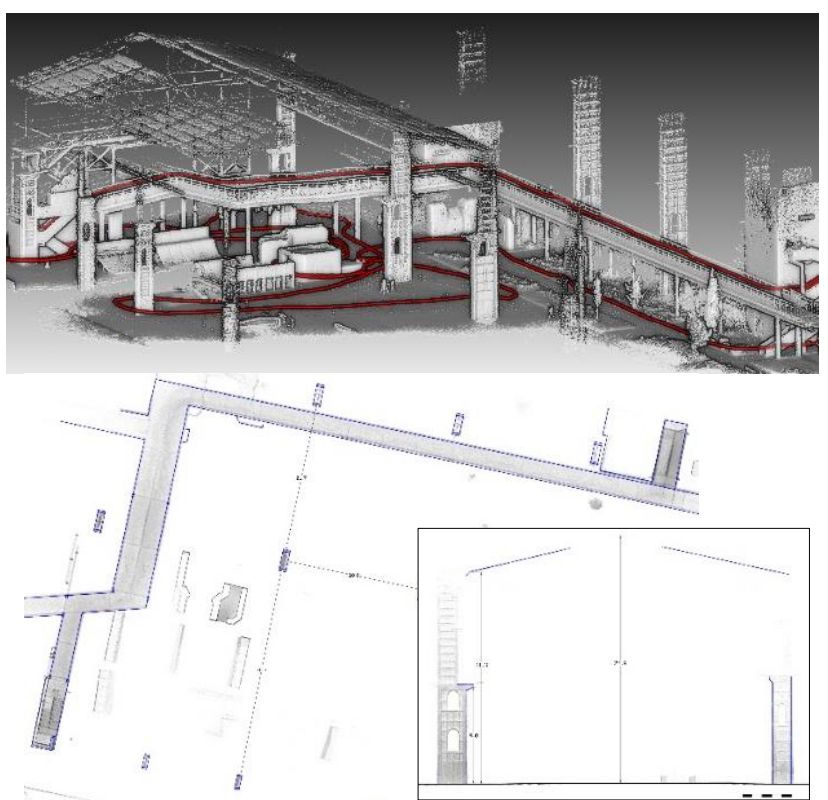

Figure 8. (top) Point cloud derived from ZEB Revo with the trajectory highlighted in red. (down) Horizontal and vertical cross-section extracted from ZEB point cloud

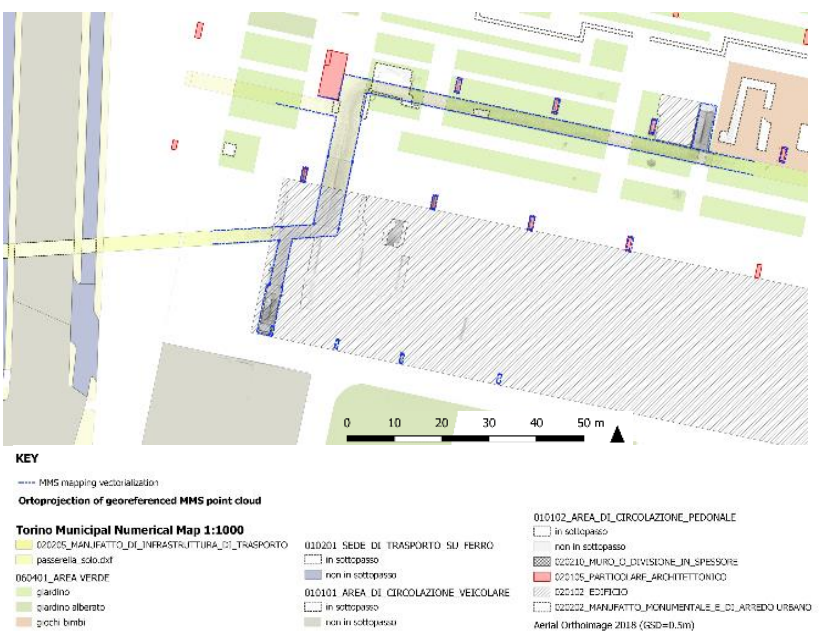

Figure 9. The comparison between digital mapping 1:1000 and dense cloud plan derived from ZEB Revo (blue vector), for mapping and building scale updating

\subsection{Urban scale navigation with panoramic images}

In the actual cities the widespread web community makes available both a large amount of geospatial data to be shared and integrated by crowdsourcing purposes and to be converted in useful information, beyond the just metric points of view. At the same times, countless web map portals are on line available to navigate in $2 \mathrm{D} / 3 \mathrm{D}$ images, most often continuously upload and update by users. A lot of them are used in literature to provide accurate and rather real time data to update urban databases and open data digital map (Cheng et al., 2018; Mooney\&Minghini, 2017; Neuhold et al., 2017; Brovelli et al., 2016).

Some of them allows the uploading and sharing of spherical or panoramic images, such as:
$O S M$, whose database is almost complete and updated in this area Mappillary, that have lack of complete data in this area - Google streetmap, that is absent under the shed as well. In the experienced test area (figure 10), it is possible to export the geo-localized and measurable terrestrial panoramas to be imported and shared in most common geo-spatial data platforms e.g.: Google Earth (KML or KMZ formats), both from V10 imaging rover and $360^{\circ}$ Fusion camera (as declared from the last release platform).

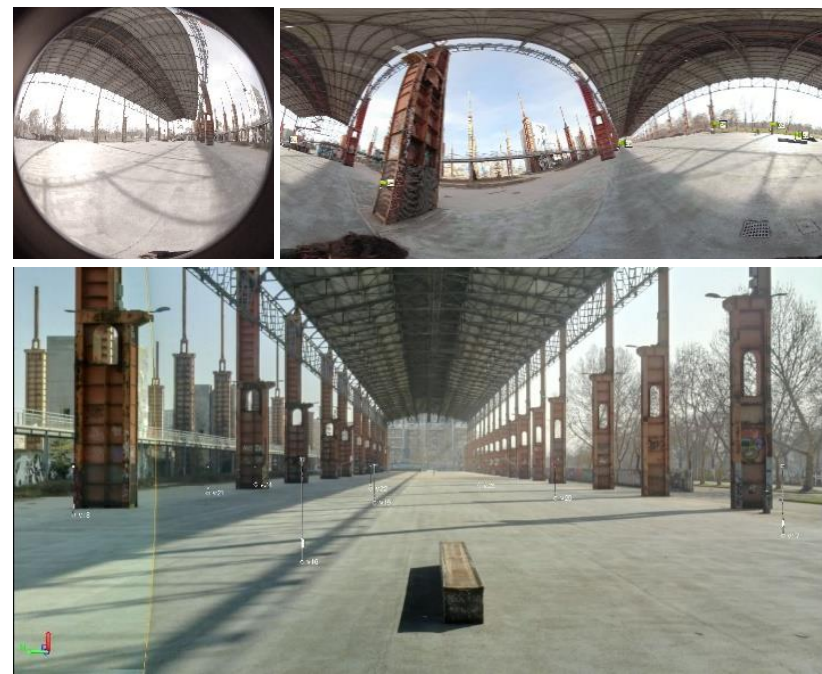

Figure 10. An example of spherical image from GoPro Fusion $360^{\circ}$ (one fish-eye hemisphere), and planar view; (bottom) adjusted camera station points from V10 Trimble rover.

\section{CONCLUSION AND FUTURE PERSPECTIVES}

Large cities as Turin can count today on a very conspicuous availability of spatial data easily accessible through SDI. It is equally true that the transformation phenomena are sudden and it is necessary to be ready and foresee the evolutionary directions to govern them; therefore, a continuous monitoring of the existing built heritage and changing urban landscape is extremely necessary. This paper has shown how the availability of historical photograms and current DTMs, produced for the most varied purposes, can allow reasoning on the transformations in place to allow future forecasts. On the other hand, the quick, handily and portable mapping systems are assuming a significant relevance in the panorama of terrestrial systems, and on their use can be highlighted among the many at least two relevant aspects. The first is that efforts must be directed towards a standardization of the obtainable results, so that after a quick and altogether easy acquisition it is possible to channel the updates in the spatial databases of urban digital map in a feasible and standardized way. Terrestrial updating methods are increasingly based on crowdsourced systems and geolocated information on sharing systems such as Streetview or Mapillary are becoming a major success in terms of use, so it is urgent to study systems that allow this information to be transformed into structured geospatial data pipelines. Furthermore, 3D data retrieved from these acquisition strategies should be validated and harmonized in their aptitude to possibly converge in 3D GIS and increase the LOD at urban scale in city models, in the well-known recent challenge of structuring and modelling geospatial data using 3D GIS and last developments in interoperability for BIM parametrization at urban scale.

\section{ACKNOWLEDGEMENTS}

The study was conducted in the framework of FULL research, the Future Urban Legacy Lab interdipartimental centre at 
Politecnico di Torino (project leader Prof. M. Robiglio). A particular thank to LabG4CH@Polito, F. G. Tonolo, F. Chiabrando and L. T. Losè for the worthwhile reasoning.

\section{REFERENCES}

AA.VV. (2018). Torino Atlas. Mappe del territorio metropolitano. Urban Center Metropolitano e Rapporto Giorgio Rota-Centro Einaudi.

Adami, A. 4D City transformations by time series of aerial images. Int. Arch Photogramm. Remote Sens. Spat. Inf. Sci. - ISPRS Arch. 2015, 40, 339-344.

Akca, D. Matching of 3D surfaces and their intensities. ISPRS J. Photogramm. Remote Sens. 2007, 62, 112-121.

Biasion, A.; Dequal, S.; Lingua, A. A new procedure for the automatic production of true orthophotos. Int. Arch. Photogramm. Remote Sens. Spat. Inf. Sci. 2004, 35, 1682-1777.

Brenner, N.; Lefebvre, H.; Schmid, C.; Gandy, M.; Merrifield, A. Implosions /Eexplosions. Towards a study of planetary urbanization, Berlin, 2014

Brovelli, M.A.; Cina, A.; Crespi, M.; Lingua, A.; Manzino, A.; Garretti, L. Ortoimmagini E Modelli Altimetrici a Grande Scala-Linee Guida. CISIS, 2009, 1-149.

Brovelli, M.A.; Minghini, M.; Zamboni, G. New Generation Platforms for Exploration of Crowdsourced Geo-Data. In Earth Observation Open Science and Innovation; Springer International Publishing: Cham, 2018; pp. 219-243.

Bouziani, M.; Goïta, K.; He, D. Automatic change detection of buildings in urban environment from very high spatial resolution images using existing geodatabase and prior knowledge. ISPRS J. Photogramm. Remote Sens. 2010, 65, 143-153.

Cassatella, C.; Garnero, G.; Guerreschi, P.; Seardo, B. Recupero di riprese fotogrammetriche storiche per l'analisi e la pianificazione territoriale: il caso studio della Val Grande. Conferenza ASITA, 2015, 237-244.

Calantropio, A., Patrucco, G., Sammartano, G., \& Losè, L. T. (2018). Low-cost sensors for rapid mapping of cultural heritage: first tests using a COTS Steadicamera. Applied Geomatics, 10(1), 31-45.

Cera, V., \& Campi, M. (2017). Evaluating the potential of imaging rover for automatic point cloud generation. The International Archives of Photogrammetry, Remote Sensing and Spatial Information Sciences, 42, 147.

Cheng, L.; Yuan, Y.; Xia, N.; Chen, S.; Chen, Y.; Yang, K.; Ma, L.; Li, M. (2018). Crowd-sourced pictures geo-localization method based on street view images and 3D reconstruction. ISPRS J. Photogramm. Remote Sens, 141, 72-85.

Feurer, D.; Vinatier, F. Joining multi-epoch archival aerial images in a single SfM block allows 3-D change detection with almost exclusively image information. ISPRS J. Photogramm. Remote Sens. 2018, 146, 495-506.

Fiat (a cura di), Le Ferriere Piemontesi, Torino 1937 from, "Parco Dora", "Ferriere Piemontesi" in Museo Torino: http://www.museotorino.it/

Fondazione Vera Nocentini (a cura di), Torino che cambia. Dalle Ferriere alla Spina 3: una difficile transizione, Ed. Angolo Manzoni, Torino 2009

Groot R. and McLaughlin J., 2000, Geospatial Data Infrastructure: Concepts, Cases and Good Practice, New York: Oxford University Press.

Gruen, A.; Huang, X.; Qin, R.; Du, T.; Fang, W.; Boavida, J.; Oliveira, A. Joint Processing of Uav Imagery and Terrestrial Mobile Mapping System Data for Very High Resolution City Modeling. Int. Arch. Photogramm. Remote Sens. Spat. Inf. Sci. 2013, XL, 4-6.

INSPIRE European Directive 'INfrastructure for Spatial Information in Europe' (INSPIRE), European Directive Developed by the European Parliament and the Council on the 14th of March, 2007 (Directive 2007/2/EC), http://inspire.ec.europa.eu/ (accessed 11/03/2019).

IntesaGIS, Specifiche per la realizzazione dei data base topografici di interesse generale. 2004

Haala, N., Peter, M., Kremer, J., \& Hunter, G. (2008). Mobile LiDAR mapping for 3D point cloud collection in urban areas-A performance test. Int. Arch. Photogramm. Remote Sens. Spat. Inf. Sci, 37, 1119-1127.

Katsikis, N. On the Geographical Organization of World Urbanization. MONU 2014, 20, 4-11.
Kossieris, S.; Kourounioti, O.; Agrafiotis, P.; Georgopoulos, A. Developing a low-cost system for 3D data acquisition. ISPRS - Int Arch. Photogramm. Remote Sens. Spat. Inf. Sci. 2017, XLII-2/W8, 119126.

Macay Moreia, J.M.; Nex, F.; Agugiaro, G.; Remondino, F.; Lim, N.J. From DSM to 3D building models: a quantitative evaluation. ISPRS - Int Arch. Photogramm. Remote Sens. Spat. Inf. Sci. 2013, XL-1/W1, 213-219.

Matikainen, L.; Hyyppä, J.; Ahokas, E.; Markelin, L.; Kaartinen, H.; Automatic Detection of Buildings and Changes in Buildings for Updating of Maps. Remote Sens. 2010, 2, 1217-1248.

Micusik, B.; Kosecka, J. Piecewise planar city 3D modeling from street view panoramic sequences. In Proceedings of the 2009 IEEE Conference on Computer Vision and Pattern Recognition; IEEE, 2009; Vol. 2009 IEEE, pp. 2906-2912.

Mooney, P.; Minghini, M. A Review of OpenStreetMap Data. In Mapping and the Citizen Sensor; Ubiquity Press, 2017; pp. 37-59.

Murakami, H.; Nakagawa, K.; Hasegawa, H.; Shibata, T.; Iwanami, E. Change detection of buildings using an airborne laser scanner. ISPRS $J$. Photogramm. Remote Sens. 1999, 54, 148-152.

Nebiker, S.; Lack, N.; Deuber, M.; Nebiker, S.; Lack, N.; Deuber, M. Building Change Detection from Historical Aerial Photographs Using Dense Image Matching and Object-Based Image Analysis. Remote Sens. 2014, 6, 8310-8336.

Neuhold, G.; Ollmann, T.; Rota Bulo, S.; Kontschieder, P. The Mapillary Vistas Dataset for Semantic Understanding of Street Scenes. 2017, 4990-4999.

Nocerino, E.; Menna, F.; Remondino, F.; Toschi, I.; RodríguezGonzálvez, P. (2017) Investigation of indoor and outdoor performance of two portable mobile mapping systems. In Proceedings of the Videometrics, Range Imaging, and Applications XIV, edited, SPIE 2017; Remondino, F., Shortis, M.R., Eds.; 2017; p. 103320I.

Nocerino, E., Menna, F., and Remondino, F.: Multi-temporal analysis of landscapes and urban areas, Int. Arch. Photogramm. Remote Sens. Spatial Inf. Sci., XXXIX-B4, 2012, 85-90, https://doi.org/10.5194/isprsarchivesXXXIX-B4-85-2012,

Patias, P.; Kaimaris, D.; Stylianidis, E. Change Detection in Historical City Centers Using Multi-Source Data: The Case of Historical Center of Nicosia-Cyprus. XXIII CIPA Symp. 2011.

$\mathrm{Pu}, \mathrm{S}$.; Vosselman, G. Knowledge based reconstruction of building models from terrestrial laser scanning data. ISPRS J. Photogramm. Remote Sens. $\mathbf{2 0 0 9}, 64,575-584$.

Puente, I.; González-Jorge, H.; Martínez-Sánchez, J.; Arias, P. Review of mobile mapping and surveying technologies. Measurement 2013, 46, $2127-2145$.

Qin, R.; Tian, J.; Reinartz, P. 3D change detection - Approaches and applications. ISPRS J. Photogramm. Remote Sens. 2016, 122, 41-56.

Remondino, F.; Spera, M.G.; Nocerino, E.; Menna, F.; Nex, F. State of the art in high density image matching. Photogramm. Rec. 2014, 29, 144-166.

Rodríguez-Gonzálvez, P.; Jiménez Fernández-Palacios, B.; MuñozNieto, Á.; Arias-Sanchez, P.; Gonzalez-Aguilera, D. Mobile LiDAR System: New Possibilities for the Documentation and Dissemination of Large Cultural Heritage Sites. Remote Sens. 2017, 9, 189.

Rottensteiner, F.; Sohn, G.; Gerke, M.; Dirk, J.; Breitkopf, U.; Jung, J. ISPRS Journal of Photogrammetry and Remote Sensing Results of the ISPRS benchmark on urban object detection and 3D building reconstruction. ISPRS J. Photogramm. Remote Sens. 2014, 93, 256-271.

Sammartano, G.; Spanò, A. Point clouds by SLAM-based mobile mapping systems: accuracy and geometric content validation in multisensor survey and stand-alone acquisition. Appl. Geomatics 2018, $10,317-339$

Stal, C.; Tack, F.; De Maeyer, P.; De Wulf, A.; Goossens, R. Airborne photogrammetry and lidar for DSM extraction and 3D change detection over an urban area - a comparative study. Int. J. Remote Sens. 2013, 34, $1087-1110$.

Teo, T.-A.; Shih, T.-Y. Lidar-based change detection and change-type determination in urban areas. Int. J. Remote Sens. 2013, 34, 968-981.

Toschi, I.; Ramos, M.M.; Nocerino, E.; Menna, F.; Remondino, F.; Moe, K.; Poli, D.; Legat, K.; Fassi, F. (2017). Oblique photogrammetry 
supporting 3D urban reconstruction of complex scenarios. The International Archives of Photogrammetry, Remote Sensing and Spatial Information Sciences, XLII-1/W1, 519-526.

Tucci, G.; Visintini, D.; Bonora, V.; Parisi, E. Examination of Indoor Mobile Mapping Systems in a Diversified Internal/External Test Field. Appl. Sci. 2018, 8, 401.

Turek, A.; Salach, A.; Markiewicz, J.; Maciejewska, A.; Zawieska, D. An Example of Multitemporal Photogrammetric Documentation and Spatial Analysis in Process Revitalisation and Urban Planning. In Proceedings of the Proceedings of the 4th International Conference on Geographical Information Systems Theory, Applications and Management; SCITEPRESS - Science and Technology Publications, 2018; pp. 223-230.

Vosselman, G.; Maas, H.-G. Airborne and terrestrial laser scanning; Whittles Publishing, 2010; ISBN 9781904445876.

Xu, S.; Vosselman, G.; Elberink, S.O. Multiple-entity based classification of airborne laser scanning data in urban areas. 2014, 88, 1-15.

Zlot, R.; Bosse, M.; Greenop, K.; Jarzab, Z.; Juckes, E.; Roberts, J. Efficiently capturing large, complex cultural heritage sites with a handheld mobile 3D laser mapping system. J. Cult. Herit. 2014, 15, 670-678. 